\title{
Recurrent Childhood Gliomatosis Cerebri
}

National Cancer Institute

\section{Source}

National Cancer Institute. Recurrent Childhood Gliomatosis Cerebri. NCI Thesaurus. Code C115366.

The reemergence of gliomatosis cerebri in childhood after a period of remission. 